\title{
Light-induced retinal injury enhanced neurotrophins secretion and neurotrophic effect of mesenchymal stem cells in vitro
}

\author{
Lesão de retina induzida por luz aumentou a secreção de neurotrofinas e o efeito neurotrófico \\ das células primordiais mesenquimais in vitro
}

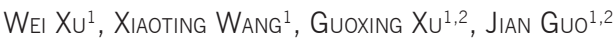

\begin{abstract}
Purpose:To investigate neurotrophins expression and neurotrophic effect change in mesenchymal stem cells (MSCs) under different types of stimulation.

Methods: Rats were exposed in 10,000 lux white light to develop light-induced retinal injury. Supernatants of homogenized retina (SHR), either from normal or light-injured retina, were used to stimulate MSCs. Quantitative real time for polymerase chain reaction (RT-PCR) and enzyme-linked immunosorbent assay (ELISA) were conducted for analysis the expression change in basic fibroblast growth facto (bFGF), brain-derived neurotrophic factor (BDNF) and ciliary neurotrophic factor (CNTF) in MSCs after stimulation. Conditioned medium from SHR-stimulated MSCs and control MSCs were collected for evaluation their effect on retinal explants.

Results: Supernatants of homogenized retina from light-injured rats significantly promoted neurotrophins secretion from MSCs $(p<0.01)$. Conditioned medium from mesenchymal stem cells stimulated by light-injured SHR significantly reduced DNA fragmentation $(p<0.01)$, up-regulated $b c l-2(p<0.01)$ and down-regulated bax $(p<0.01)$ in retinal explants, displaying enhanced protective effect.

Conclusions: Light-induced retinal injury is able to enhance neurotrophins secretion from mesenchymal stem cells and promote the neurotrophic effect of mesenchymal stem cells.
\end{abstract}

Keywords: Fibroblast growth factor 2; Ciliary neurotrophic factor; Retina/inju ries; Mesenchymal stromal cells; Stem cells; Brain-derived neurotrophic factor

\section{RESUMO}

Objetivo: Investigar a expressão de neurotrofinas e mudança no efeito neurotrófico de células-tronco mesenquimais (MSCs) sob diferentes tipos de estimulação.

Métodos: Os ratos foram expostos em 10.000 lux de luz branca para desenvolver a lesão da retina induzida por luz. Os sobrenadantes de homogeneizado de retina (SHR) quer a partir de retina normal ou da lesada por luz, foram usados para estimular as células-tronco mesenquimais. O RT-PCR quantitativa e ELISA foram realizados para análise da alteração de expressão do fator básico de crescimento de fibroblastos (bFGF), do fator neurotrófico derivado do cérebro (BDNF) e do fator neurotrófico ciliar (CNTF) em MSCs após a estimulação. O meio condicionado de células-tronco mesenquimais estimuladas por SHR e controles foram coletadas para avaliação de seu efeito sobre os explantes de retina.

Resultados: SHR de retinas de rato lesadas porluz promoveram aumento significativo de secreção de neurotrofinas em MSCS $(p<0,01)$. O meio condicionado de SHR lesado porluz reduziu significativamente a fragmentação do DNA de MSCs $(p<0,01)$, elevação de $B C l-2(p<0,01)$ e redução de bax $(p<0,01)$ em explantes de retina, mostrando um aumento do efeito protetor.

Conclusões: A lesão da retina induzidos pela luz é capaz de aumentar a secreção de neurotrofinas e promover o efeito neurotrófico de células-tronco mesenquimais.

Descritores: Fator 2 de crescimento de fibroblastos; Fator neurotrófico ciliar; Retinal lesões: Células mesenquimais estromais; Células-tronco; Fator neurotrófico derivado do encéfalo

\section{INTRODUCTION}

Mesenchymal stem cells (MSCs) are self-renewal and multipotent cell source widely existed in mesenchymal tissues, which play a significant role in tissue regeneration and injury repair. It has been reported that MSCs are able to differentiate into multilineage tissue cell $s^{(1)}$, including retinal cells $s^{(2,3)}$, making MSCs an alternative therapeutic source for some irreversible retinal disorders such as age-related macular degeneration (AMD), retinitis pigmentosa (RP), glaucoma. However, clinical cell replacement is still far away unless technical barriers like directional differentiation, large scale output of target cells and reconstruction of the complicated network among the existed retinal cells and the regenerated cells were overcome. In addition, heterogeneous populations like multipotent adult progenitor cells (MAPCs), marrow-isolated adult multilineage inducible (MIAMI) cells, multipotent adult stem cells (MASCs) and very small embryonic-like stem cells (VSELs) may overlap in MSCs ${ }^{(4)}$. The emerging evidence that MSCs are pericytes for the common features they shared ${ }^{(5)}$. These make MSCs a controversial cell source. Nonetheless, MSCs are promising for its potential applications in neuroprotection and immunomodulation apart from tissue regeneration.

Accumulating findings have indicated a neuroprotective role of MSCs in central nervous system (CNS) disorder as well as in retinal disorder. Neurotrophins secreted from MSCs promote the survival of host cells and the repair process during injury enabling MSCs an attractive therapeutic source for a variety of neurological disease, e.g. multiple sclerosis and stroke ${ }^{(6)}$. Neurotrophic effect of MSCs was also reported in retinal disorders. MSCs attenuated cell death in retinal ganglion cells (RGCs) suffering from in vitro insult ${ }^{(7)}$ and promoted RGCs survival in glaucoma animal model ${ }^{(8)}$. Systemic administration of MSCs delayed progress of retinal degeneration in RCS rats ${ }^{(9)}$. These
Submitted for publication: September 24,2012

Accepted for publication: January 31, 2013

Study carried out at Department of Ophthalmology, First Affiliated Hospital of Fujian Medical University.

Department of Ophthalmology, First Affiliated Hospital of Fujian Medical University, Fuzhou City, China.

2 Fujian Institute of Ophthalmology, Fuzhou City, China.
Funding: This work was supported by National Natural Science Foundation of China (No.81271026) and Innovative Platform Foundation of Fujian Province, China (No.2010Y2003).

Disclosure of potential conflicts of interest: W.Xu, None; X.Wang, None; G.Xu, None; J.Guo, None. Correspondence address: Guoxing Xu. Department of Ophthalmology. First Affiliated Hospital of Fujian Medical University. 20 Chazhong Road, Fuzhou City 350005 (China)

E-mail: fjmuxuguoxing@126.com 
suggested potential application of MSCs for neuroprotection in retinal diseases.

Cytokines secreted from MSCs might involve in the neurotrophic effect. Therefore, we quantitatively analyzed neurotrophins expression change in MSCs stimulated by light-induced retinal injury in an in vitro model to evaluate their potential roles in retinal neuroprotection.

\section{METHODS}

\section{Animals}

All animal procedures in this study were in accordance with the Association for Research in Vision and Opthalmology (ARVO) Statement for the Use of Animals in Ophthalmic and Vision Research. Sprague-Dawley (SD) rats (6 to 8 weeks of age) were maintained in cyclic light condition (80 lux, 12 hours on-off) and had access to food and water ad libitum before use.

\section{LIGHT-INDUCED RETINAL INJURY}

Rats were exposed to 10,000 lux white light for 24 hours in separate cages and the pupils were dilated with atropine ointment. After light exposure, rats underwent dark adaptation for 24 hours. For evaluation of light-induced injury, rats were randomly selected after light exposure and dark adaptation and euthanized. The eyes were enucleated, fixed and embedded. The eye sections were stained for terminal deoxynucleotidyl transferase-mediated dUTP nick end labeling (TUNEL) using a kit (Roche) in accordance with the manufacturer's protocol.

\section{SUPERNATANTS OF HOMOGENIZED RETINA (SHR) PREPARATION}

Normal and light damaged rats were sacrificed respectively. The retinas were harvested for supernatants of homogenized retina (SHR) preparation under a sterile condition as previously described ${ }^{(10)}$. Briefly, retinas were homogenized in Dulbecco's modified Eagle's medium (DMEM) (Gibco). The suspensions were centrifuged at 12,000 g, $4^{\circ} \mathrm{C}$ for $20 \mathrm{~min}$. The supernatants were obtained and diluted to a final protein concentration at $200 \mu \mathrm{g} / \mathrm{ml}$, and supplemented with $2 \% \mathrm{vol} / \mathrm{vol}$ fetal bovine serum (FBS) (Gbico), penicillin (100 U/ml) and streptomycin $(100 \mu \mathrm{g} / \mathrm{ml})$ and stored at $-20^{\circ} \mathrm{C}$ before use.

\section{Cell culture}

SD rat mesenchymal stem cells (Cyagen) were cultured in mesenchymal stem cell growth medium (Cyagen). Cells from passage 3-5 were used for this study. When the cells reached $70 \%$ confluence, the media was changed to either normal or light-damaged SHR and renewed every 2 days. MSCs cultured in 2\% FBS+DMEM were set as control. After 2 days and 5 days culture, MSCs were rinsed in phosphate-buffered saline (PBS) twice and maintained in DMEM for 24 hours in humidified incubator with $5 \% \mathrm{CO}_{2}$ at $37^{\circ} \mathrm{C}$. The supernatants were collected and centrifuged at $12000 \mathrm{~g}, 4^{\circ} \mathrm{C}$ for $20 \mathrm{~min}$.

\section{Retinal explants culture}

Normal rats were sacrificed. Retinas were harvested and radically dissected into four equal-sized pieces. The pieces were randomly transferred into 24-well plate pre-added $500 \mu$ l supernatant collected from different groups of MSCs and supplemented with 1\% B27+N2 (Invitrogen) in each well. Retinal explants were cultured for 24 hours in humidified incubator with $5 \% \mathrm{CO}_{2}$ at $37^{\circ} \mathrm{C}$ and harvested for cell death detection and histology analysis. Three conditioned media were used for retinal explants culture, which were conditioned medium (CM) from control MSCs (CM-MSCs), conditioned medium from normal SHR stimulated MSCS (CM-NSHR) and conditioned medium from light-injured SHR stimulated MSCs (CM-ISHR). Retinal explants cultured in DMEM supplemented with 1\% B27+N2 were set as control.

\section{Quantitative ReAL time-POlymerase Chain REACTION (RT-PCR) ANALYSIS}

Total RNA from both MSCs and retinal explants was isolated using RNeasy Mini Kit (Qiagen) according to the manufacturer's protocol and treated with RNase free DNase to eliminate genomic DNA contamination. Two microgram total RNA was reverse transcribed into cDNA with PrimeScript ${ }^{\circledR} 1^{\text {st }}$ strand cDNA Synthesis Kit (Takara). Realtime polymerase chain reaction (PCR) was performed on an Agilent Stratagene Mx3000P QPCR Systems using SYBR ${ }^{\circledR}$ Premix Ex Taq ${ }^{\text {TM }}$ Kit (Takara). Primer sets were listed in table 1. glyceraldehyde-3-phosphate dehydrogenase (GAPDH) was used as an endogenous control. Real-time PCR data was analyzed using comparative CT method ${ }^{(11,12)}$.

\section{ENZYME-LINKED IMMUNOSORBENT ASSAY}

Supernatants from MSCs were tested for the protein levels of bFGF, brain-derived neurotrophic factor (BDNF), CNTF using ELISA kit (Cusabio) according to the manufacturer's instructions. For retinal cell death detection, an ELISA kit (Roche) was used to assay DNA fragmentation in retinal explants. The explants were gently rinsed in PBS twice and homogenized in $200 \mu$ lysis buffer. The following procedures were in accordance with manufacturer's protocol.

\section{Histological analysis}

Retinal explants were fixed for 24 hours at $4^{\circ} \mathrm{C}$ by replacing the media with $4 \%$ paraformaldehyde. With minimal damage, the explants were in situ infiltrate with $30 \%$ sucrose for 24 hours at $4^{\circ} \mathrm{C}$, embedded in OCT and frozen. The frozen tissue was adjusted to enable a cross section. The sections were transferred to slides pretreated with polylysine. The slices were stained with hematoxylin and eosin for histological analysis.

\section{Statistical analysis}

Data and statistical analysis were performed using SPSS software (version 19.0). Data are given as mean \pm SEM. Analysis of variance (ANOVA) was conducted for comparison of neurotrophins expression and neurotrophic effect among groups at two time points. Statistical significance was set at $\mathrm{P}<0.05$.

\section{RESULTS}

\section{LIGHT-INDUCED RETINAL INJURY}

Retinal injury was induced after intensive light exposure for $24 \mathrm{~h}$, as indicated by TUNEL staining (Figure 1). Apoptotic cells sparsely dispersed among the layers of retina with the majority in outer nuclear layer (ONL). The ONL thickness was slightly reduced. Part of nuclei in the ONL disappeared, forming a serrated shape.

\section{Morphology of MSCs after stimulation}

MSCs growth was slow down in media containing $2 \% \mathrm{vol} / \mathrm{vol}$ FBS. Most cells maintained their fibroblast-like morphology, while a

Table 1. Primer sets for RT-qPCR

\begin{tabular}{lcc}
\hline & \multicolumn{1}{c}{ Sense } & Antisense \\
\hline bFGF & 5'-TTCCCACCCGGCCACTTCAAG-3' & 5'-GTTCGCACACACTCCCTTGA-3' \\
CNTF & 5'-AAACACCTCTGACCCTTCAC-3' & 5'-AGTCATCTCACTCCAACGAT-3' \\
BDNF & 5'-GGAGCCTCCTCTGCTCTTT-3' & 5'-TTTTGATACCGGGACTTTCT-3' \\
Bax & 5'-GTGGTGCCCTCTTCTACTTTG-3' & 5'-CACAAAGATGGTCACTGTCTGC-3' \\
BCl-2 & 5'-ACGAGTGGGATACTGGAGATG-3' & 5'-TAGCGACGAGAGAAGTCATCC-3' \\
GAPDH & 5'-GGAAACCCATCACCATCTTC-3' & 5'-TGGTCACACCCATCACAAA-3' \\
\hline
\end{tabular}


small amount of cells grew out long processes and connected with each other, especially after 5 days stimulation by either normal SHR or light-injured SHR. These cells displayed typical neuronal appearance (Figure 2). In contrast, cells cultured in 2\% vol/vol FBS+DMEM did not display neuronal morphology.

\section{Change in neurotrophins expression}

Quantitative RT-PCR showed mRNA levels of bFGF, BDNF and ciliary neurotrophic factor (CNTF) were up-regulated both in normal SHR (NSHR) stimulation group $(p<0.01)$ and light-injured SHR (ISHR) stimulation group $(p<0.01)$ in contrast to control group. However, no significant difference was detected in protein levels between NSHR stimulation group and control group ( $p>0.05)$. Light-injured SHR (ISHR) stimulation promoted neurotrophins secretion from MSCs. The concentration of bFGF was $255 \pm 11 \mathrm{ng} / \mathrm{ml}$ after ISHR stimulation for 5 days versus $102 \pm 7 \mathrm{ng} / \mathrm{ml}$ in control group. BDNF increased from $17.8 \pm 1.4 \mathrm{pg} / \mathrm{ml}$ in control group to $24.6 \pm 2.4 \mathrm{pg} / \mathrm{ml}$ ( 2 days) and 45.2 $\pm 3.0 \mathrm{pg} / \mathrm{ml}$ (5 days) in ISHR stimulation group. The concentration of ciliary neurotrophic factor (CNTF) was also identified up-regulation

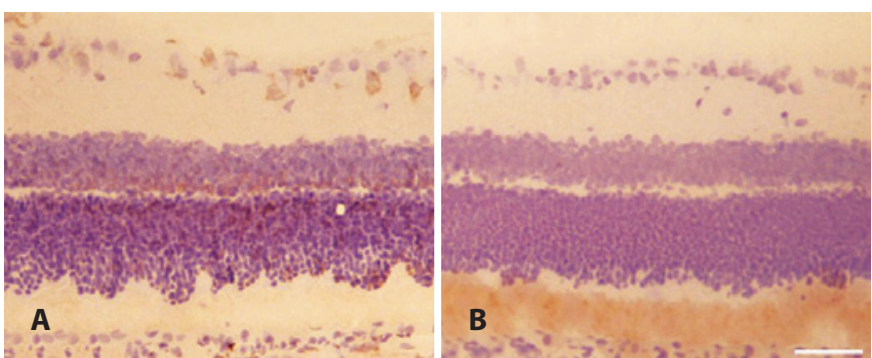

Figure 1. TUNEL staining for evaluation of light-induced retinal injury. Apoptotic cells distributed mainly in the outer nuclear layer (ONL) after light exposure, ONL thickness was slightly reduce, part of the outer nuclei disappeared forming a serrated edge (A) No positive staining was identified in control retina (B). ONL,. Scale bar indicates $50 \mu \mathrm{m}$. from $118 \pm 14 \mathrm{pg} / \mathrm{ml}$ to $216 \pm 14 \mathrm{pg} / \mathrm{ml}$ after 5 days of ISHR stimulation (Figure 3).

\section{NeURoprotective efFECt OF CONDITIONED MEDIA}

$\mathrm{BCl}-2$ and bax expression in retinal explants were identified for evaluation the neuroprotective effect of conditioned medium from control MSCS (CM-MSCS), conditioned medium from normal SHR stimulated MSCS (CM-NSHR) and conditioned medium from lightinjured SHR stimulated MSCS (CM-ISHR). CM-ISHR, CM-NSHR and CM-MSCs induced up-regulation of bcl- 2 in contrast to control group. CM-ISHR and CM-MSCs also induced down-regulation of bax (Figure 4A, B, p < 0.05). In addition, CM-ISHR induced bcl-2 up-regulation and bax down-regulation more significantly in comparison with the rest two groups, suggesting a better neurotrophic effect. Calculation of bcl-2/bax ratio among groups showed all conditioned media significantly increased bcl-2/bax ratio with the max in CM-ISHR group (Figure 4C, $\mathrm{p}<0.01$ ).

DNA fragmentation was analyzed in retinal explants for evaluation cell death inhibition effect of conditioned media. All three conditioned media significantly reduced DNA fragmentation (Figure $4 D, p<0.01$ ). Among the conditioned media, CM-ISHR displayed the best preservative effect on retinal explants.

Histological analysis showed retinal explants underwent severe destruction after 24 hours culture. The tissue lysed and ripped, especially in the explants cultured in control medium. The major damage appeared in the inner nuclear layer (INL) and the ganglion cell layer (GCL). However, the explants cultured in CM-ISHR group were best preserved. All layers of retina were tightly attached, except from disrupture of the outer segment (Figure 5).

\section{DISCUSSION}

Potential applications of MSCs include the plasticity, neuroprotection and immunomodulation ${ }^{(13)}$. Due to various cytokines secreted from MSCs might involve in the process of tissue repair ${ }^{(14)}$, previous attention that merely focused on the differentiation of MSCs into
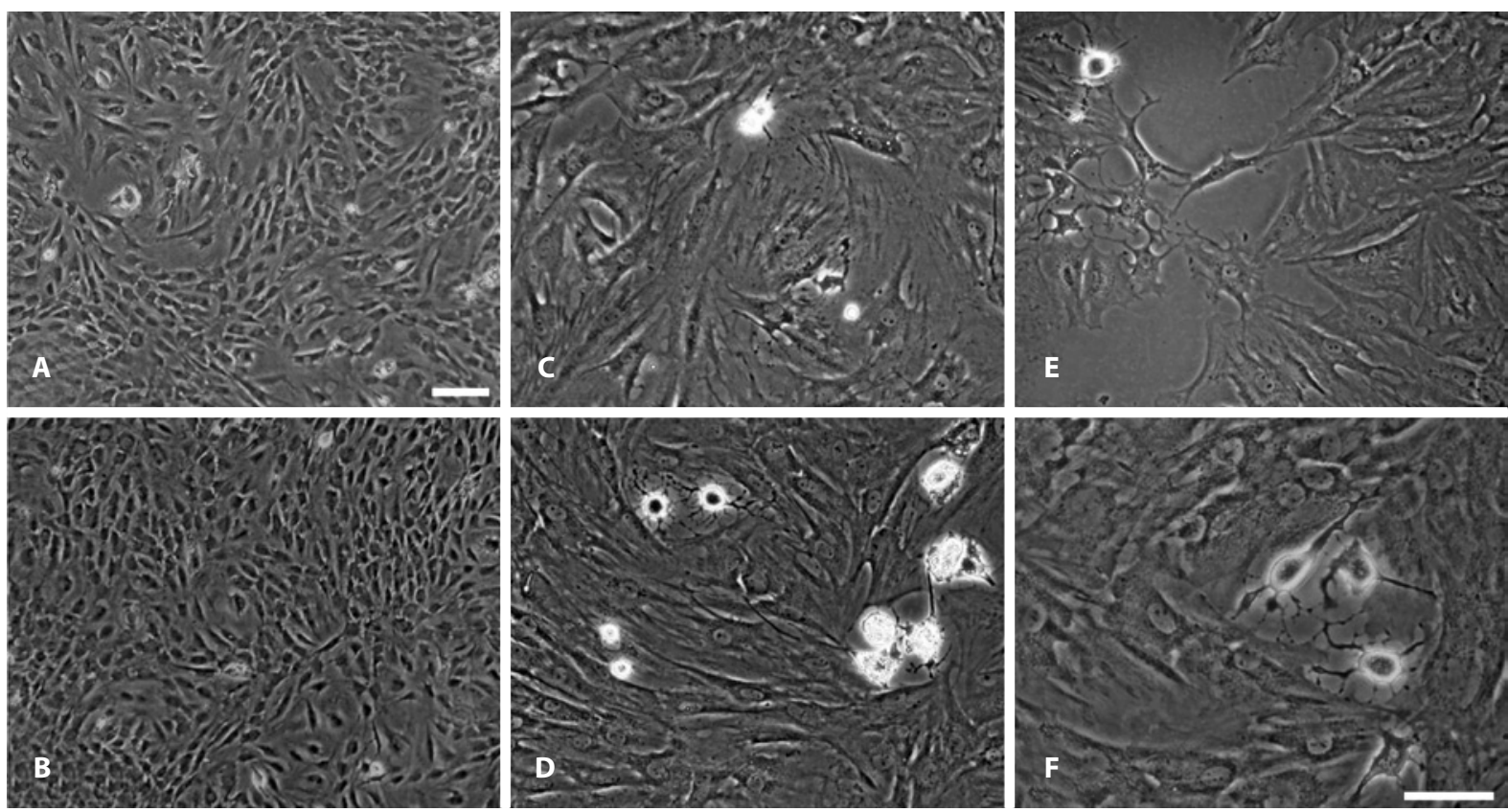

Figure 2. Morphology of MSCs cultured in different media for 2 days (A, C, E) and 5 days (B, D, F). Cells cultured in 2\% FBS+DMEM remained fibroblast-like shape $(A, B)$. However, a small amount of cells grew out multiple processes and connected with each other, displaying neuronal appearance in normal SHR (C, D) and light-injured SHR (E, F) stimulated MSCs. Scale bars indicate $100 \mu \mathrm{m}$. 


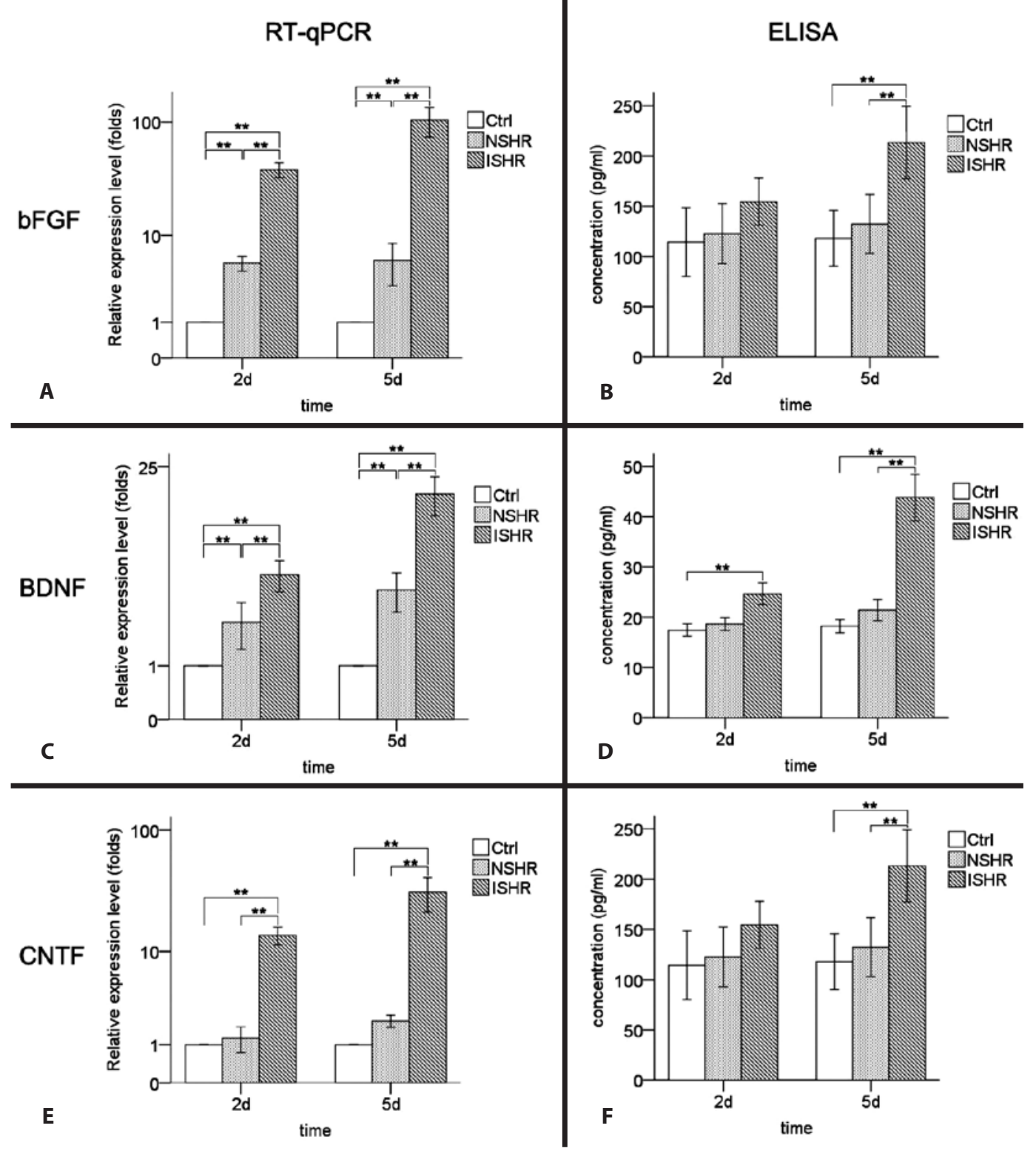

Ctrl= control MSCs; NSHR= MSCs stimulated by normal SHR; ISHR= MSCs stimulated by light-injured SHR. ${ }^{*} \mathrm{P}<0.01$.

Figure 3. Neurotrophins expression in MSCs after stimulation. Both mRNA levels $(A, C, E)$ and protein levels $(B, D, F)$ were induced up-regulation by ISHR. Although bFGF and BDNF expression in MSCs stimulated by NSHR were identified significant difference in mRNA level, no difference was identified in protein level (D).

target cells has changed. Therefore, this cell source was considered as a drugstore during injury ${ }^{(15)}$. The three therapeutic potentials of MSCs should be placed at an equally important position, especially when directional differentiation of MSCs into target cells and effective integration of target cells into the complex retinal neuro-network are still unavailable. Our results revealed that light-induced retinal injury was able to promote neurotrophins secretion in MSCs and consequently enhanced the retinal protective effect. This offers the possibility to take advantage of MSCs as modulators during retinal injury. Moreover, the therapeutic potential of MSCs can be enhanced by pre-stimulation.

Cytokines involved in retinal injury varied depending on the types of injury that retina suffered. Light-induced retinal injury was a well-established model, as confirmed by TUNEL staining. CNTF and bFGF are two major trophic factors which play significant roles in light-induced retinal degeneration ${ }^{(16)}$. Both fibroblast growth factor receptor (FGFR) and CNTFR $\alpha$ are localized on photoreceptors suggesting direct effects of these two neurotrophins on photoreceptors ${ }^{(17)}$. Although BDNF do not impact directly on photoreceptors, it has photoreceptor rescue effect though the activation of glial cell ${ }^{(18)}$. Thus these neurotrophic factors were selected in our study.

Reports have shown that both systemic administration and local administration of MSCs were found to be beneficial to retinal disorders. The protective effect of MSCs does not necessarily need a full integration of the graft to the host tissue ${ }^{(6)}$, which indicated that the neurotrophic effect of MSCs did not depend on the differentiation of the transplanted cells. MSCs are able to enhance myelin formation without differentiation ${ }^{(19)}$. In addition, a variety of neurotrophins were identified expression in MSCs that contribute to the protective effect in tissue repair. The cell source acts as mediators during repair 
bcl-2
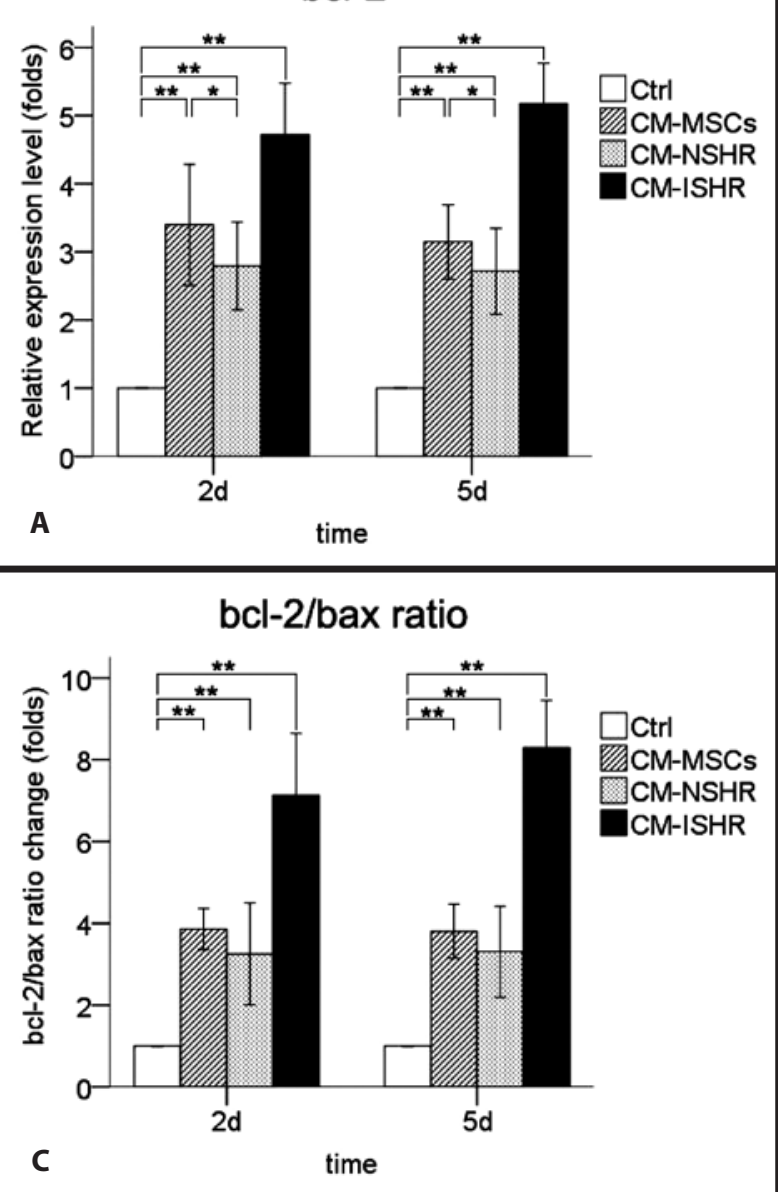

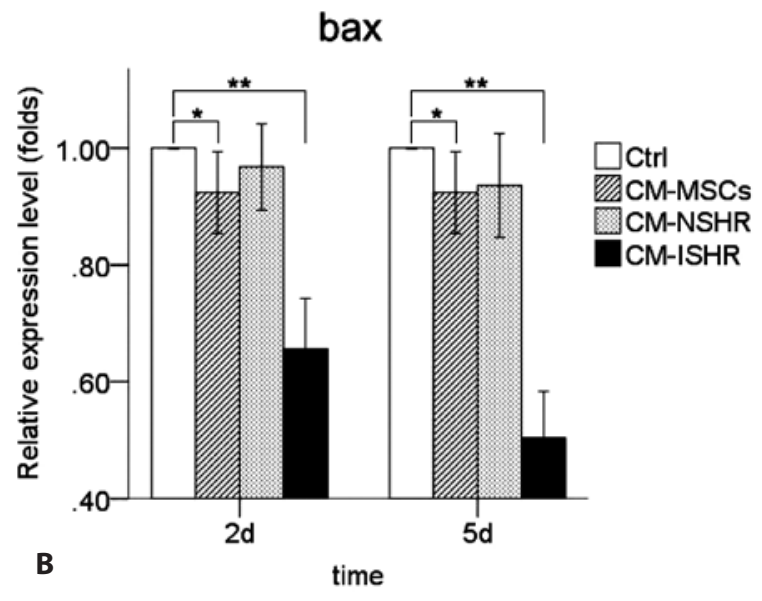

cell death detection

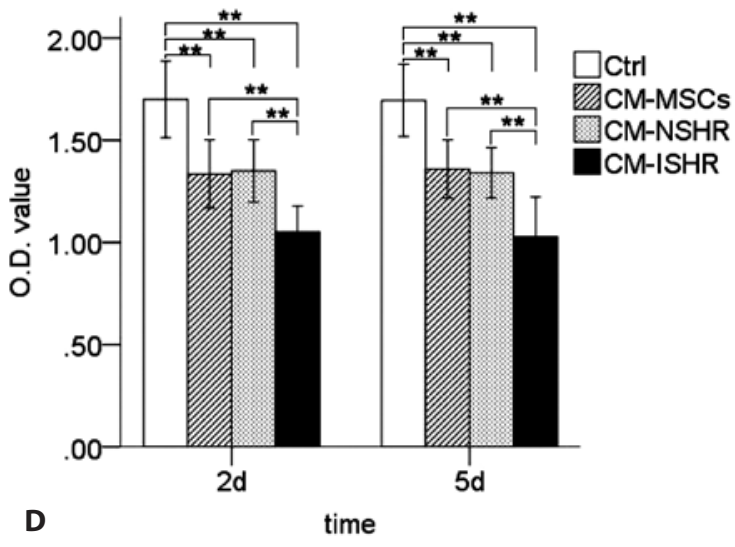

$\mathrm{Ctrl}=$ control medium; $\mathrm{CM}-\mathrm{MSC}=$ conditioned medium from control MSCs; CM-NSHR= conditioned medium from MSCs stimulated by normal SHR; $\mathrm{CM}-\mathrm{ISHR}=$ conditioned medium from MSCs stimulated by light-injured SHR. ${ }^{*} \mathrm{P}<0.05,{ }^{* *} \mathrm{P}<0.01$.

Figure 4. Neurotrophic effect of conditioned media from different groups. Conditioned media increased bcl-2 expression and ratio of bcl-2/bax in retinal explants (A, C). Bax expression decreased in CM-ISHR group (B). DNA fragmentation also reduced in conditioned media, with minimal in CM-ISHR group (D).
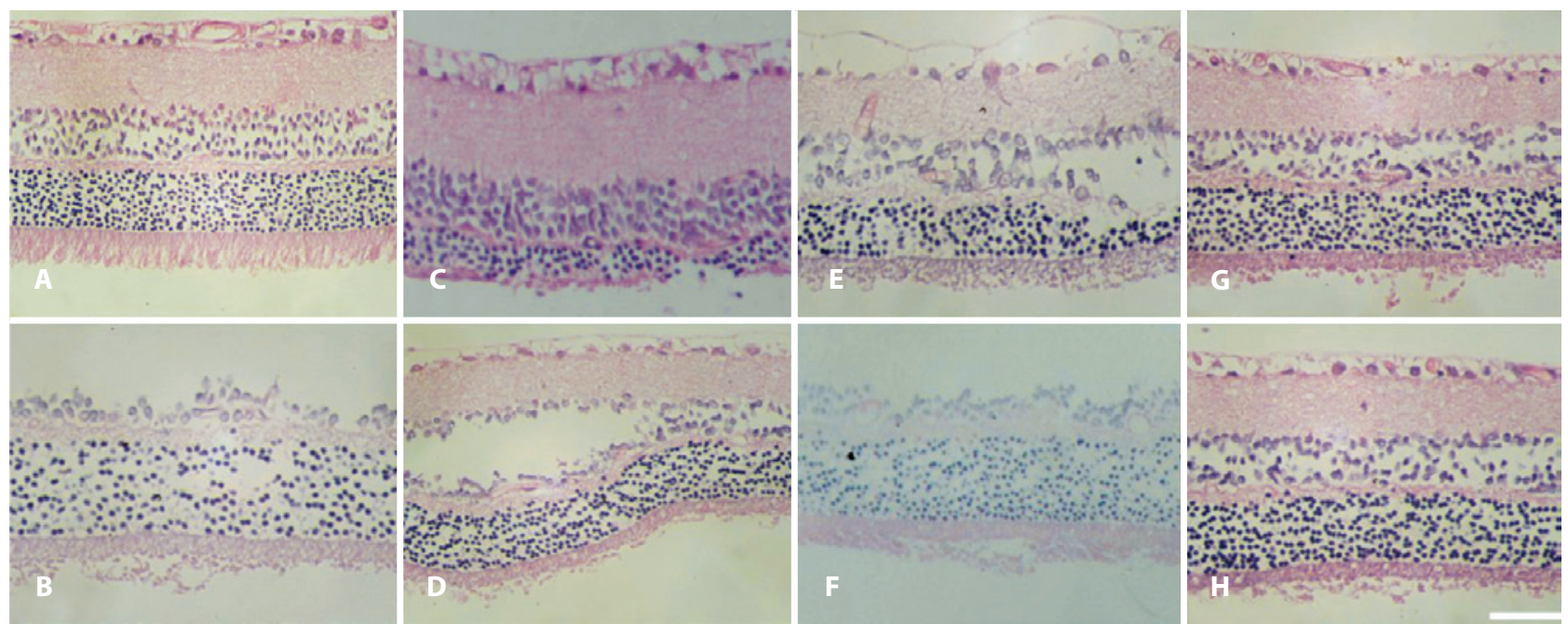

Figure 5. Hematoxylin and eosin staining for retinal explants. The cultured explants severely lysed and ripped in contrast to fresh explant (A). Only the ONL remained in control medium group (B). CM-MSCs for 2 days (C) and 5 days (D) displayed protective effect on retinal explants. CM-NSHR for 2 days (E) was neurotrophic, however, the trophic effect decreased in CM-NSHR for 5 days (F). The tissue structure was better preserved in CM-ISHR for 2 days (G) and 5 days (H). ONL, outer nuclear layer; CM-MSCs, conditioned medium from control MSCs; CM-NSHR, conditioned medium from normal SHR; CM-ISHR, conditioned medium from light-injured SHR. Scale bar indicates $50 \mu \mathrm{m}$. 
process in tissue injury. Possible mechanism might be that MSCs enhance survival of host cells through cytokines secretion and promote endogenous regeneration through interaction with host cells. It should be mentioned that the interaction between MSCs and the host cells also requires intercellular signal transmission, probably the cytokines. It is not clear to what extend neurotrophins secretion from MSCs play a role in retinal injury. However, our results by quantitative analysis of the diverse neurotrophins change in response to light-induced retinal injury suggested that a wide spectrum of neurotrophins might be up-regulated in MSCs where injury existed. Use of an in vitro model for retinal neuroprotection screening provides a convenient way for evaluation neurotrophic effect of MSC $s^{(20)}$. Retinal explants underwent progressive degeneration during in vitro culture. Therefore, we set 24-hour culture as a point for assessment of the protective effect. The results suggested that neurotrophic effect of MSCs was significantly enhanced by injury stimulation. Nevertheless, the condition ex vivo was different from the pathological process in vivo, further investigations are necessary.

Our results showed that conditioned medium (CM) from control MSCs also displayed a protective effect on retinal explants. This was in accordance with the previous report by Inoue et al. that conditioned medium from MSCs promoted retinal cell survival in vitro ${ }^{(21)}$. CM from normal SHR stimulated MSCs was also identified to be neurotrophic. However, the protective effect was weaker in contrast to CM from control MSCs, as detected that bcl-2 expression level was lower. One possible explanation is that MSCs stimulated by normal SHR might undergo neuronal differentiation, thus altered the biological function and consequently led to decreased neuroprotective effect. Though MSCs stimulated by light-injured SHR might also display neuronal differentiation, the situation was more complicated due to the coexisted injury response. The results were also distinct. Insight into the interactions between retinal injury and MSCs response could be achieved via a co-culture system, but long term survival and better functional preservation of retinal cells in vitro are yet to be settled.

Two factors that might impact on the protective effect of MSCs are cell passages and growth density. Therefore, we selected MSCs from passage 3 to passage 5 which maintained the biological function more similar to in vivo condition and stimulated the cells when reaching a confluence of $70 \%$ which kept the cells at relatively equal growth situation. The cells stimulated by both SHRs seemed to undergo differentiation, as the morphological change was identified. However, Choi et al. ${ }^{(22)}$, reported no significant variation of the MSCs surface markers after pretreatment. Some authors ${ }^{(23)}$ identified return of differentiated MSCs to undifferentiated state. Although previous work by Zhang et al.(10), demonstrated neuronal markers expression on MSCs after light-injured SHR stimulation using a similar model, we did not test the neuronal or retinal markers on MSCs, since stimulation of MSCs for 2 days and 5 days was not long enough for a stable differentiation. In addition, only a small amount of cells were identified undergoing morphological change. Even though, these durations were able to induce up-regulation of neurotrophins. The up-regulation of neurotrophins secretion in MSCs, especially bFGF, probably contributed to retinal differentiation and act as a positive feed-back during differentiation, as was reported that bFGF was superior in inducing MSCs to express retinal neuron-specific markers ${ }^{(24)}$. The dramatic expression change of these neurotrophins after injury stimulation implicated significant roles they play in MSCs response to retinal injury, but further investigations into the correlation between neurotrophins secretion from MSCs and their neurotrophic effect is necessary.

\section{CONCLUSION}

We found that light-injured SHR stimulation significantly increased neurotrophins secretion and neurotrophic effect of MSCs. Since using MSCs for neuroprotection is currently a more practicable way over cell replacement, our study provided an alternative therapeutic potential for enhancing the trophic effect of MSCs.

\section{REFERENCES}

1. Jiang $Y$, Jahagirdar BN, Reinhardt RL, Schwartz RE, Keene CD, Ortiz-Gonzalez XR et al. Pluripotency of mesenchymal stem cells derived from adult marrow. Nature. 2002;418(6893):41-9. Comment in: Nature. 2002;418(6893):1. Nature. 2002;418(6893): 25-7. Nature. 2007:447(7146):763.

2. Kicic A, Shen WY, Wilson AS, Constable IJ, Robertson T, Rakoczy PE. Differentiation of marrow stromal cells into photoreceptors in the rat eye. J Neurosci. 2003;23(21): 7742-9.

3. Castanheira P, Torquetti L, Nehemy MB, Goes AM. Retinal incorporation and differentiation of mesenchymal stem cells intravitreally injected in the injured retina of rats. Arq Bras Oftalmol. 2008;71(5):644-50.

4. Ratajczak MZ, Zuba-Surma EK, Machalinski B, Ratajczak J, Kucia M. Very small embryonic-like (VSEL) stem cells: purification from adult organs, characterization, and biological significance. Stem Cell Rev. 2008:4(2):89-99.

5. Crisan M, Yap S, Casteilla L, Chen CW, Corselli M, ParkTS, et al. A perivascular origin for mesenchymal stem cells in multiple human organs. Cell Stem Cell. 2008;3(3):301-13. Comment in: Cell Stem Cell. 2008;3(3):229-30.

6. Uccelli A, Laroni A, Freedman MS. Mesenchymal stem cells for the treatment of multiple sclerosis and other neurological diseases. Lancet Neurol. 2011;10(7):649-56.

7. Harper MM, Adamson L, Blits B, Bunge MB, Grozdanic SD, Sakaguchi DS. Brain-derived neurotrophic factor released from engineered mesenchymal stem cells attenuates glutamate- and hydrogen peroxide-mediated death of staurosporine-differentiated RGC-5 cells. Exp Eye Res. 2009;89(4):538-48.

8. Johnson TV, Bull ND, Hunt DP, Marina N, Tomarev SI, Martin KR. Neuroprotective effects of intravitreal mesenchymal stem cell transplantation in experimental glaucoma. Invest Ophthalmol Vis Sci [Internet]. 2010[cited 2012 Jan 3];51(4):2051-9.Available from: http://www.iovs.org/cgi/pmidlookup?view=long\&pmid=19933193

9. Wang S, Lu B, Girman S, Duan J, McFarland T, Zhang QS, et al. Non-invasive stem cel therapy in a rat model for retinal degeneration and vascular pathology. PLoS One. 2010;5(2):e9200.

10. Zhang Y, Wang W. Effects of bone marrow mesenchymal stem cell transplantation on light-damaged retina. Invest Ophthalmol Vis Sci [Internet]. 2010[cited 2011 Jun 21];51(7):3742-8.Available from: http://www.iovs.org/cgi/pmidlookup?view=long\&p mid $=20207980$

11. Livak KJ, Schmittgen TD. Analysis of relative gene expression data using real-time quantitative PCR and the 2(-Delta Delta C(T)) Method. Methods. 2001;25(4):402-8.

12. Schmittgen TD, Livak KJ. Analyzing real-time $P C R$ data by the comparative $C(T)$ method. Nat Protoc. 2008;3(6):1101-8.

13. Xu W, Xu GX. Mesenchymal stem cells for retinal diseases. Int J Ophthalmol. 2011 4(4):413-21

14. Stappenbeck TS, Miyoshi $H$. The role of stromal stem cells in tissue regeneration and wound repair. Science. 2009;324(5935):1666-9.

15. Caplan Al, Correa D. The MSC: an injury drugstore. Cell Stem Cell. 2011;9(1):11-5.

16. Joly S, Pernet V, Chemtob S, Di Polo A, Lachapelle P. Neuroprotection in the juvenile rat model of light-induced retinopathy: evidence suggesting a role for FGF-2 and CNTF. Invest Ophthalmol Vis Sci [Internet]. 2007[cited 2012 Jul 21];48(5):2311-20. Available from: http://www.iovs.org/content/48/5/2311.long

17. Valter K, Bisti S, Gargini C, Di Loreto S, Maccarone R, Cervetto L, et al. Time course of neurotrophic factor upregulation and retinal protection against light-induced damage after optic nerve section. Invest Ophthalmol Vis Sci [Internet]. 2005[cited 2010 Jul 21];46(5):1748-54.Available from: http://www.iovs.org/content/46/5/1748.long

18. Saito $T$, Abe $T$, Wakusawa $R$, Sato $H$, Asai $H$, Tokita-Ishikawa $Y$, et al. TrkB-T1 receptors on Muller cells play critical role in brain-derived neurotrophic factor-mediated photoreceptor protection against phototoxicity. Curr Eye Res. 2009;34(7):580-8.

19. Arriola A, Kiel ME, Shi Y, McKinnon RD. Adjunctive MSCs enhance myelin formation by xenogenic oligodendrocyte precursors transplanted in the retina. Cell Res. 2010; 20(6):728-31.

20. Bull ND, Johnson TV, Welsapar G, DeKorver NW, Tomarev SI, Martin KR. Use of an adult rat retinal explant model for screening of potential retinal ganglion cell neuroprotective therapies. Invest Ophthalmol Vis Sci [Internet]. 2011 [cited 2012 Oct 21] 52(6):3309-20.Available from: http://www.iovs.org/content/52/6/3309.long

21. Inoue $Y$, Iriyama A, Ueno S, Takahashi H, Kondo M, Tamaki Y, et al. Subretinal transplantation of bone marrow mesenchymal stem cells delays retinal degeneration in the RCS rat model of retinal degeneration. Exp Eye Res. 2007;85(2):234-41.

22. Choi YJ, Li WY, Moon GJ, Lee PH, Ahn YH, Lee G, et al. Enhancing trophic support of mesenchymal stem cells by ex vivo treatment with trophic factors. J Neurol Sci. 2010; 298(1-2):28-34.

23. Sun $X$, Ge J, Jiang R, Duan S, Song G, Duan $Y$, et al. Induced differentiation of bone marrow mesenchymal stem cells towards retinal ganglion precursor cells. Cell Res. 2008;18(s76).

24. Liu DN, Yin ZQ, Wu N, Wang YH, Chen LF. Rat bone marrow stromal cells express retinal phenotypic markers following different induction protocols. Ophthalmic Res. 2009;41(4):186-93. 